\title{
Economia e criminalidade: uma avaliação dos custos da violência para o município de Governador Valadares, MG
}

\author{
Economics and crime: the cost of violence for the municipality of Governador \\ Valadares, MG \\ Economía y criminalidad: una evaluación de los costos de la violencia para el \\ municipio de Governador Valadares, MG
}

\author{
Hilton Manoel Dias Ribeiro ${ }^{1}$ \\ Oline Silva Freitas ${ }^{1}$
}

Recebido em 18/08/2018; revisado e aprovado em 28/04/2019; aceito em 06/05/2019

DOI: http://dx.doi.org/10.20435/inter.v22i2.2126

\begin{abstract}
Resumo: O município de Governador Valadares, MG, registrou aproximadamente 280 mil habitantes e estava na 5 a posição no ranking estadual de violência, em 2015. O objetivo deste trabalho é mensurar os custos econômicos gerados em decorrência da violência intencional contra terceiros neste município. Por meio do método da contagem, foram mensurados os custos públicos, privados e as perdas sociais decorrentes da violência. Os resultados indicam que o valor agregado destas três categorias de custo, no ano de 2015, chegou a aproximadamente 5,8\% do PIB municipal.
\end{abstract}

Palavras-chave: crime; custos; contagem; perdas sociais; Governador Valadares.

\begin{abstract}
The municipality of Governador Valadares, MG, has approximately two hundred and eighty thousand inhabitants and remained in 5th place in the state ranking of violence in 2015 . We measured, through the accountability methodology, public costs, private costs, and social losses resulting from violence. The results indicate that the aggregate value of these three cost categories, in the year 2015, reached approximately the equivalent of $5.8 \%$ of the municipal GDP.

Keywords: crime; costs; counting; social losses; Governador Valadares.

Resumen: El municipio de Governador Valadares, MG, posee, aproximadamente, 280 mil habitantes y estaba en la quinta posición en el ranking estadual de violencia, en 2015. Así, el objetivo de este trabajo es medir los costos económicos generados como consecuencia de la violencia intencional contra terceros en este municipio. A través del método de la cuenta se midieron los costos públicos, privados y las pérdidas sociales derivadas de la violencia. Los resultados indican que el valor de estas tres categorías de costo, en 2015, Ilegó a aproximadamente el 5,8\% del PIB municipal.
\end{abstract}

Palabras clave: crimen; costos; pérdidas sociales; Governador Valadares.

\section{INTRODUÇÃO}

A violência é um problema que afeta e preocupa todas as camadas sociais, sendo determinante para avaliação do nível de bem-estar social de uma população. Pode ser definida como ato de violentar, estado de violência, opressão e abuso de força, caracterizando-se como ato criminoso, normalmente, quando se ferem direitos e leis formalmente constituídas. Destaca-se que a violência tem diferentes facetas, que vão desde a agressão verbal e psicológica à agressão física, seja esta letal ou não. A análise deste trabalho se concentra na violência intencional contra terceiros, caracterizada pela agressão física, podendo resultar em morte. Assim, considerando a Classificação Internacional de Doenças (CID 10), segundo a Organização Mundial da Saúde (OMS, 2017a), tem-se "mortes violentas por causas externas".

De acordo com a OMS (2017b), aproximadamente 3.800 pessoas são mortas diariamente no mundo, vítimas de algum tipo de violência. Essa estatística, além de corroborar a violência

\footnotetext{
${ }^{1}$ Universidade Federal de Juiz de Fora (UFJF), Governador Valadares, Minas Gerais. Brasil.
} 
como um problema de saúde pública, levanta questões sobre seu impacto em termos dos custos socioeconômicos para combatê-la. Ainda, segundo a OMS, 90\% das mortes violentas acontecem em países onde há grande disparidade na distribuição de renda, atingindo principalmente os mais jovens. Entre as causas mais latentes da violência, tem-se a baixa escolaridade, a fragilidade financeira e a desestruturação familiar.

Dado que segurança é um direito universal, segundo a Organização das Nações Unidas (ONU, 1948), cabe ao Estado, na maior parte das vezes, atuar de forma direta no intuito de combater a violência já existente e buscar meios de combater e inibir o acesso às armas e às drogas, uma vez que estes fatores, entre outros, estão fortemente correlacionados ao surgimento de conflitos interpessoais e situações de violência, os quais podem levar a perdas sociais, financeiras, má alocação dos recursos públicos, sentimento de insegurança e impunidade, influenciando a tomada de decisão de todos os agentes da sociedade.

Segundo Caprirolo, Jaitman e Mello (2017), o Brasil é um dos países que apresentam, em termos nominais, os mais elevados custos de crime. Em 2014, a violência custou US\$75,894 milhões para o país. Esse valor representa 53\% do custo total da criminalidade existente na América Latina e no Caribe e 78\% no Cone Sul (Argentina, Brasil, Chile, Paraguai e Uruguai), a taxas de câmbio de 2014. Esse alto custo pode ser parcialmente explicado pelas dimensões continentais do país, que tem cerca de $79,2 \%$ da população do Cone Sul e é responsável por $95,1 \%$ dos homicídios desta região. Deve-se considerar ainda que as estimativas gerais revelam que a criminalidade custa, em média, para os países da América Latina e Caribe, 3\% do PIB.

Especialmente sobre o município de Governador Valadares, localizado no estado de Minas Gerais, este possui aproximadamente 280 mil habitantes, segundo o Instituto Brasileiro de Geografia e Estatística (IBGE, 2018), e estava na 5a posição no ranking estadual de violência, em 2015. O município apresentou uma taxa de 40,6 homicídios para cada 100 mil habitantes, índice quase duas vezes superior ao da capital (Belo Horizonte), que possui taxa de 24,4 homicídios a cada 100 mil habitantes (CERQUEIRA et al., 2017). Assim, a partir dessa realidade, o objetivo deste trabalho é mensurar e analisar os custos econômicos gerados em decorrência da violência intencional contra terceiros no município de Governador Valadares, MG. Como método, empregase o de contagem, sendo possível mensurar os custos econômicos da criminalidade e violência, apresentando os resultados como razão proporcional do Produto Interno Bruno (PIB) local.

Conforme Almeida (2012), ao analisar questões relacionadas à violência, além dos fatores econômicos e sociais, é preciso atentar-se para as especificidades regionais, dado que a diversidade de cada região pode apresentar-se como variável-chave para compreensão do problema em nível local. Segundo Santos e Abreu (2009), o município de Governador Valadares teve seu processo urbanístico desenvolvido de forma desordenada. O resultado da ocupação não planejada é o surgimento de grandes aglomerados urbanos, marcados pelas desigualdades e vulnerabilidades socioeconômicas, criando um ambiente favorável ao aumento da criminalidade.

Além desta introdução, o trabalho segue dividido em mais quatro seções. A segunda apresenta as teorias que se destacam na análise econômica da violência e os resultados empíricos recentes envolvendo o debate sobre custos da violência. A terceira apresenta o método de contagem e a base de dados, seguida da quarta seção, com os resultados e discussões. Por fim, tem-se as considerações finais na última seção. 


\section{ESTUDOS DO CRIME: ABORDAGENS TEÓRICAS E EMPÍRICAS}

Entre as correntes teóricas sobre crime e comportamento, três delas se destacam, a saber: a Economia do Crime (BECKER, 1968); a Teoria das Oportunidades do Crime (COHEN; FELSON, 1979); e os Neomarxistas (QUINNEY, 1979). A primeira, formulada pelo Nobel em economia Gary Becker, aponta que a decisão de um agente da sociedade em praticar atos criminosos é baseada nas incertezas em torno desta ação. O agente social fará uma análise do custo-benefício de se cometer um crime de cunho econômico, buscando atingir seu ótimo, que é obter algum tipo de lucro da ação criminosa sem sofrer tipo algum de dano, seja financeiro, seja de privação da liberdade ou da vida (CERQUEIRA; LOBÃO, 2004).

Já a Teoria das Oportunidades do Crime, segundo Cohen e Felson (1979 apud SANTOS; CASAGRANDE; HOECKEL, 2015), indica que a ocorrência de delitos econômicos pode ser considerada algo inerente à vida em sociedade e que, se um indivíduo perceber uma oportunidade que resulta em um retorno financeiro suficientemente atraente, e que o alvo desta ação esteja desprotegido o suficiente, a ocorrência do delito será inevitável.

Com um caráter analítico mais atento às questões sociais, Richard Quinney dedicou boa parte de seu tempo para construir, a partir de uma visão Neomarxista, um extenso arcabouço teórico a respeito da justiça criminal. Segundo Quinney (1979), as atividades criminosas são fruto das próprias inconsistências do sistema capitalista, tais como crises, desemprego, desigualdade e concentração de renda, que são circunstâncias capazes de promover comportamentos destruidores da ordem social.

No que se refere aos estudos empíricos, Fearone e Hoeffler (2014) mostram que os custos sociais dos homicídios equivalem a $1,7 \%$ do PIB mundial, enquanto os custos das guerras civis equivalem a aproximadamente $0,2 \%$ do PIB mundial. No Brasil, a cifra da perda anual de bemestar social relacionada à violência letal, conforme Cerqueira (2014), é de aproximadamente $1,8 \%$ do PIB. Estimativas como estas evidenciam a gravidade do problema e a necessidade de se pensar estratégias para minimizá-lo.

Almeida e Guanzirol (2013) buscaram testar a aplicabilidade da teoria da economia do crime e a teoria da desorganização social para explicar os determinantes dos crimes contra patrimônio e contra a vida na região metropolitana de Belo Horizonte, para o ano de 2007. Seus resultados revelam que o dispêndio do Estado em ações que promovem a participação dos jovens em atividades de esporte e lazer, assim como o investimento em melhorias do sistema de justiça e força policial, contribui para a diminuição dos crimes contra o patrimônio. Já as variáveis de cunho social, tais como o aumento da religiosidade e a diminuição da vulnerabilidade infantil, mostram-se significativas na redução dos crimes contra a vida.

Conforme Santos e Kassouf (2008), embora haja muita divergência na literatura a respeito das principais causas das altas taxas de crimes, incluindo os homicídios, nas várias regiões do Brasil, é consensual que estas são explicadas principalmente por questões socioeconômicas. Diante disso, Loureiro e Carvalho-Junior (2007), Marques Junior (2014), Thomé e Vonbun (2017) buscaram avaliar o impacto de variáveis de caráter assistencialista sobre as taxas de homicídios, concluindo que investimentos em tais variáveis se mostraram mais robustos na redução dos homicídios do que os gastos com segurança pública, tendo este último um resultado mais efetivo no sentido de reprimir a violência do que de combatê-la.

Sapori (2007) argumenta que os estados e os municípios brasileiros têm custeado a maior parte dos gastos com segurança pública, quando se compara com a União. No entanto nada 
se pode dizer quanto à eficiência desses gastos, uma vez que, mesmo havendo aumentos no repasse para os setores relativos ao combate da violência, ao longo dos anos, nem sempre estes aumentos foram sob a forma de capacitação de profissionais ou aquisição de equipamentos, concentrando-se em aumentos salariais e gastos com a previdência policial.

No entanto Kahn (1999) destaca que, quando ocorre de um custo ter capacidade de prevenção, deve ser considerado como investimento, como no caso de contratação por parte do governo de novos servidores públicos para a área da segurança e/ou implementação de projetos educacionais que contribuirão para um ambiente social menos violento.

Há um entendimento, na literatura nacional (PEIXOTO; ANDRADE; AZEVEDO, 2008; CERQUEIRA; MOURA, 2013; CERQUEIRA, 2016; BECKER; KASSOUF, 2017), de que é preciso haver um equilíbrio entre as diretrizes públicas voltadas tanto para a prevenção quanto para o controle das situações de maior incidência da violência. Conforme resultados encontrados por Peixoto, Andrade e Azevedo (2008) e por Loureiro e Carvalho-Junior (2007), as políticas de caráter preventivo, principalmente na fase infantojuvenil, têm um maior custo efetivo ante as políticas de repressão e controle. Neste sentido, aumento dos investimentos em educação e manutenção do adolescente na escola, redistribuição de renda e ampliação do aparato da segurança pública se apresentam como ferramentas capazes de reverter as altas taxas de homicídios no país, sendo preciso também garantir que tais políticas sejam executadas de maneira eficiente.

Na mensuração dos custos gerados pela violência, há uma variedade de classificações destes custos, tais como: tangíveis e intangíveis, diretos e indiretos, endógenos e exógenos. No entanto, apesar desta variedade, os trabalhos buscam identificar uma diferenciação, de maneira desagregada, dos custos assumidos pela sociedade e pelo Estado (BANCO INTERAMERICANO DE DESARROLLO [BID], 1997; INSTITUTO DE ESTUDOS DA RELIGIÃO [ISER], 1998; KAHN, 1999; TEIXEIRA, 2005).

Ao investigar os custos tangíveis e intangíveis gerados pela violência, três metodologias recebem destaque na literatura: a valoração contingente, os preços hedônicos e a contagem. Na primeira, os pesquisadores buscam mensurar o quanto as pessoas estão dispostas a pagar para que haja mudanças positivas em determinado quadro social que gera externalidades negativas. Desta forma, é possível avaliar quais políticas públicas são consideradas prioridades pela sociedade beneficiária (TEIXEIRA, 2005; CERQUEIRA, 2014).

A abordagem dos preços hedônicos, por sua vez, busca identificar o montante financeiro que um indivíduo está disposto a pagar para obter algum nível de satisfação. A partir de modelagem econométrica, fazem-se estimações do valor de bens que não têm um preço direto no mercado. Em outras palavras, esta metodologia busca precificar algum nível de perda de bem-estar ou quanto as pessoas estarão dispostas a pagar a mais para ter algum ganho no seu bem-estar. A sua principal limitação é o fato de exigir um grande número de observações desagregadas (RONDON, 2003; TEIXEIRA, 2005; CERQUEIRA, 2014).

Por fim, o método da contagem busca somar os custos financeiros impostos à sociedade em razão da violência e apresentá-los como proporção do PIB local, para determinado ano. A pesquisa feita no Brasil (Rio de Janeiro), no ano de 1995, utilizando esta abordagem quantitativa, considerou os custos que vão desde o atendimento médico às vítimas da violência até os custos relacionados às perdas de produção do mercado de trabalho. Embora os gastos privados em segurança não tenham sido contabilizados nesta pesquisa, concluiu-se que o montante gasto com segurança foi próximo de $5 \%$ do PIB do Rio de Janeiro, naquele ano (ISER, 1998). 
Aplicando também o método da contagem, Rondon e Andrade (2003) buscaram estimar os custos gerados pela violência intencional contra terceiros, no município de Belo Horizonte, para o ano de 1999. Os autores analisaram gastos com segurança privada e seguros, por parte das famílias, e segurança pública por parte do Estado. Além destes, consideraram também gastos relativos ao sistema de saúde, impacto da violência intencional na expectativa de vida e volume de bens roubados ou furtados. Entre os resultados apresentados, considerando as possibilidades de rendimento das vítimas de homicídios, conforme seu respectivo gênero e idade, os prejuízos acarretados pela violência intencional contra terceiros seriam de, aproximadamente, $R \$ 174,5$ milhões, em 1999. Os gastos com segurança pública ocuparam a primeira posição dos custos da violência na capital mineira para aquele ano, com um montante aproximado de $R$ \$ 340,7 milhões, o equivalente a $1,58 \%$ do PIB de Belo Horizonte.

Em estudo semelhante, Teixeira (2005) analisou os custos da criminalidade em Curitiba, para o ano de 2002. O autor dividiu os custos em encargos públicos, que são os custos pagos pela sociedade de maneira indireta, via recolhimento de impostos; encargos privados, que são relativos à busca privada por objetos e serviços de segurança; e, por fim, os custos sociais, relativos à perda de capital humano. Os resultados apresentados apontaram que o custo relativo à segurança pública foi equivalente a $1,26 \%$ do PIB da capital paranaense, para o ano de 2002, e que a renda potencial perdida, considerando o rendimento esperado, segundo a faixa etária e o gênero das vítimas, somou R\$ 4,9 milhões, aproximadamente.

\section{METODOLOGIA E BASE DE DADOS}

O método selecionado para avaliação dos custos da violência em Governador Valadares, MG, é o de contagem. Autores como Khan (1999), Rondon (2003) e Teixeira (2005) fizeram uso desse método para avaliar questões como a perda de capital humano, prejuízos decorrentes da violência e perfil das vítimas de violência. A estimativa dos custos totais advindos da violência intencional contra terceiros, além de poder ser utilizada como medida da perda do bem-estar social, serve como base para o direcionamento da alocação dos recursos públicos, medida comparativa para trabalhos futuros e parâmetro de avaliação do custo-benefício de políticas públicas, já adotadas no sentido de prevenção e combate à violência.

A contagem consiste na determinação prévia de certas categorias de custo, sendo seu resultado global formado pela soma dos valores de cada categoria, apresentados como proporção do PIB para determinado ano. A equação básica para contagem é descrita em (1):

Contagem $=\frac{\sum\left(\mathrm{X}_{1 \mathrm{t}}+\mathrm{X}_{2 \mathrm{t}}+\cdots \mathrm{X}_{\mathrm{nt}}\right)}{\mathrm{PIB}_{\mathrm{t}}} \times 100$

em que $X_{n t}$ representa um vetor de variáveis para cada categoria $n$ e período t; e PIB $_{t}$ representa o Produto Interno Bruto no ano t.

Esta aplicação ganhou destaque a partir dos estudos encomendados pelo Banco Interamericano do Desenvolvimento (BID), na década de 1990, que buscou avaliar os impactos econômicos da violência no Brasil, Colômbia, El Salvador, México, Peru, Estados Unidos e Venezuela. Segundo Rondon (2003) e Teixeira (2005), a principal vantagem em adotar a contagem é o fato de ela permitir trabalhar com dados parciais. Assim, a escassez de informações em determinada categoria de custo não implica em limitação significativa para o resultado final da pesquisa. Sua desvantagem, no entanto, está na possibilidade de incluir um mesmo custo em 
diversas categorias. Contudo esse tipo de medida, se acompanhada ao longo do tempo, torna-se ferramenta útil para avaliação das perdas econômicas municipais por conta da violência.

Baseado em Teixeira (2005), os custos aqui analisados estão subdivididos em encargos públicos, encargos privados diretos e perdas sociais. Segundo o autor, os encargos públicos são uma espécie de encargos privados indiretos, uma vez que se financia via receita do governo, que é gerada a partir a arrecadação de impostos pagos pelos cidadãos. A partir daqui, faz-se uma descrição dos dados, para as três categorias. A base é composta por dados de 2015. A escolha se deu pelo fato de ser o ano mais recente com disponibilidade de um maior conjunto de variáveis para o município, atendendo melhor a proposta do método escolhido.

1) Encargos públicos: são relativos aos gastos financiados e realizados pelo Poder Executivo federal, estadual e municipal. Estes encargos estão subdivididos em dois tipos: segurança pública, custódia e reintegração social; e atendimento hospitalar às vítimas da violência.

a) Segurança pública, custódia e reintegração social: conforme Teixeira (2005), para contabilizar os gastos em segurança pública, são considerados os gastos de responsabilidade da autoridade administrativa municipal e estadual. Os dados referentes aos custos municipais e estaduais são obtidos por meio da Lei Orçamentária Anual (LOA) e do Balanço Geral da Administração Direta, respectivamente. São consideradas todas as despesas relacionadas à "Segurança Pública" e à "Custódia e Reintegração Social", sendo selecionados apenas os gastos que se direcionam ao combate ou à prevenção da violência intencional. Embora seja comum encontrar a inclusão dos custos relativos ao Poder Judiciário, optou-se por não os incluir, uma vez que tais custos não estão desagregados por tipologias de crimes.

Segundo dados do Relatório Resumido de Execuções Orçamentárias do município de Governador Valadares (2016), o gasto despendido com o setor de Segurança Pública foi de, aproximadamente, $\mathrm{R} \$ 2,3$ milhões. No entanto, uma vez que não havia disponível para consulta a desagregação deste valor segundo as subcategorias do setor, optou-se por trabalhar com os gastos previstos, dada a proximidade com o valor do gasto efetivo.

Tendo em vista que as despesas relacionadas à Polícia Militar, apresentadas no Balanço Geral do Estado (2016), referem-se à totalidade dos municípios, obteve-se a quantidade do efetivo policial que está lotada no município de Governador Valadares, a partir de informações do Índice Mineiro de Responsabilidade Social (IMRS) (Fundação João Pinheiro [FJP], 2018), para se calcular a representatividade do município em relação ao total do estado. Desta forma, temse uma aproximação da despesa com segurança pública destinada ao município.

Para estimar os gastos públicos relativos à custódia e reintegração social, foram avaliados conjuntamente os dados do Balanço Geral do Estado (2016) com os dados do Departamento Penitenciário Nacional (DEPEN, 2018), para se obter a proporção da representação dos gastos penitenciários de Governador Valadares em relação ao total do estado. Assim, foi possível obter uma aproximação do montante gasto em reintegração e custódia direcionada à manutenção da população carcerária do município.

b) Atendimento hospitalar às vítimas de violência: os gastos do sistema público de saúde em decorrência da violência foram estimados a partir dos dados do Sistema de Informações Hospitalares do SUS (SIH/SUS). Nesta base de dados, é possível obter todos os valores gastos com internações hospitalares, desagregados por município, sexo, idade e a causa da internação (segundo CID-10). Embora os dados do SIH/SUS indiquem os valores repassados aos hospitais privados conveniados, estes gastos não foram considerados, pelo fato de que estas transferências não são cabíveis de desagregação. 
Uma vez que os repasses federais custeiam apenas uma parte dos gastos com internação, assume-se que os gastos com saúde estão subestimados, em virtude do estado e do município participarem também na contribuição do gasto público total, principalmente no que tange aos gastos com pessoal e equipamentos. Dado que a parte custeada pela administração estadual e municipal não é passível de discriminação, seu cálculo não foi incluído na soma global dos custos.

2) Encargos privados: os encargos privados diretos, conforme Teixeira (2005), são gastos individuais, no sentido da prevenção contra a violência. Estes gastos estão subdivididos entre contratação de profissionais da segurança e gastos com seguros. A indisponibilidade de dados não permitiu calcular gastos com equipamentos de segurança e prejuízos decorrentes de bens roubados no município de Governador Valadares.

a) Gastos com profissionais de segurança: os gastos advindos da contratação dos profissionais de segurança são estimados a partir dos dados disponibilizados, em nível municipal, pela Relação Anual de Informações Sociais (RAIS), do Ministério do Trabalho e Emprego (MTE). A partir do rendimento médio dos profissionais que ocupavam a função de vigia ou segurança particular, no município de Governador Valadares, é estimado o gasto total com a contratação destes profissionais pelo setor privado.

b) Gastos privados com seguros: os gastos privados com seguros são estimados por meio dos dados disponibilizados pela Superintendência de Seguros Privados (SUSEP). São considerados todos os ramos que se associem à prevenção da violência, a saber, seguro contra roubo, seguro de proteção veicular e seguros compreensivos de residências, condomínio e empresas. Uma vez que os seguros de proteção veicular e aqueles destinados a fins residências ou comerciais contemplam proteção não somente contra roubo e furto, assumiu-se que os gastos privados podem estar superestimados.

3) Perdas sociais: para Teixeira (2005), estas são difíceis de serem mensuradas, dada a linha tênue que divide os bens tangíveis dos intangíveis. Sequelas permanentes aos sobreviventes vítimas da violência, perdas familiares, queda de rendimento potencial por traumas relacionados à violência, entre outros, são exemplos dos custos impostos à sociedade e que são difíceis de serem mensurados. No entanto, a fim de encontrar uma aproximação do volume das perdas sociais, são avaliados os anos médios de vida perdidos e renda potencial perdida, ambos em decorrência de mortes por causas externas.

a) Anos médios de vida perdidos (AVP): é um índice de perda de bem-estar social que mede a perda de expectativa de vida atrelada a alguma causa específica de mortalidade, neste caso, as mortes violentas por causas externas. A sua construção se dá a partir da multiplicação da expectativa de vida de determinada faixa etária, pelo número de vítimas da violência, com aquela respectiva idade, dividido pelo total de indivíduos com aquela idade. A soma do quociente obtido para cada faixa etária corresponde aos anos médios de vida perdido, conforme (2):

$$
\mathrm{AP}_{\mathrm{t}}=\sum_{\mathrm{a}=0}^{\mathrm{I}}\left(\frac{\mathrm{E}(\mathrm{a}) \cdot \mathrm{d}_{\mathrm{at}}}{\mathrm{P}_{\mathrm{at}}}\right)
$$

em que $\mathrm{AP}_{\mathrm{t}}$ é igual aos anos médios de vida perdidos; $\mathrm{E}(\mathrm{a})$ é igual à esperança de vida condicionada à idade " $a$ "; $\mathrm{d}_{\mathrm{at}}$ é o total de vítimas de violência com a idade " $\mathrm{a}$ " no período " $\mathrm{t}$ "; $\mathrm{P}_{\mathrm{at}}$ é o total de indivíduos com a idade "a" no período " $\mathrm{t}$ "; e I é a idade de referência da população.

Os dados sobre a esperança de vida condicionada, E(a), e o total de indivíduos com a idade "a" $\left(\mathrm{P}_{\mathrm{at}}\right)$, foram obtidos a partir dos dados de mortalidade e da estimativa populacional, 
respectivamente, ambos para o ano de 2015, disponibilizados pelo IBGE. As informações sobre o total de vítimas de violência com a idade "a" $\left(\mathrm{d}_{\mathrm{at}}\right)$ foram obtidas por meio do Sistema de Informações sobre Mortalidade (SIM).

O uso do AVP superestima o impacto das mortes violentas por causas externas. Segundo Teixeira (2005), primeiro, por desconsiderar a possibilidade de um indivíduo vir a morrer por outros motivos; e, segundo, por considerar que exista um equilíbrio estacionário no crescimento da população. No entanto, embora estes problemas sejam reconhecidos na literatura, não é usual buscar métodos para corrigi-los.

Renda potencial perdida: a estimação da renda potencial perdida é uma análise do quanto a economia, de maneira geral, deixou de ganhar em termos de rendimento, em decorrência da morte violenta de pessoas em idade economicamente ativa (15 anos ou mais). Esta estimação é obtida por meio da multiplicação da renda média anual esperada para determinada faixa etária e grau de instrução, pelo total de vítimas em determinada idade e grau de instrução.

Para isso, foram usados os dados sobre o número de mortes por causas externas, segundo a classificação da CID-10, disponíveis no Sistema de Informação sobre Mortalidade (SIM), que informa o local de ocorrência do óbito, o sexo, a faixa etária e o grau de instrução da vítima. Estas informações foram relacionadas conjuntamente com as rendas médias, também segundo a faixa etária e o grau de instrução (separadamente), que foram estimadas com base nos dados da RAIS, para o município de Governador Valadares, para o ano de 2015.

Essa análise será feita em duas etapas. A primeira relaciona informações da renda média esperada, segundo o sexo e a faixa etária, com os dados sobre o total de vítimas de agressão, também segundo o sexo e a faixa etária. A segunda etapa pondera o rendimento médio esperado de acordo com a escolaridade das vítimas. Assim, quanto maior a escolaridade, maior o rendimento médio esperado e maior será a perda de renda potencial, e vice-versa. Estas duas etapas são úteis para identificar e comparar o perfil das vítimas quanto ao seu nível educacional.

\section{RESULTADOS E DISCUSSÕES}

Sobre os encargos públicos, a previsão de gasto da Prefeitura Municipal de Governador Valadares (PMGV) com o setor de segurança pública, para 2015, apresentou um total aproximado de $R \$ 2,4$ milhões. Este valor foi distribuído entre funções administrativas, corretivas e preventivas, no sentido de promover a segurança e inibir ou punir ações criminosas e violentas. Os dados da Tabela 1 representam os gastos municipais em segurança pública para Governador Valadares, previstos para 2015.

Tabela 1 - Previsão dos gastos municipais em segurança pública em 2015

\begin{tabular}{lcc}
\hline Destino da Despesa & $\mathbf{R}^{\mathbf{*}}$ & $\mathbf{( \% )}$ \\
\hline Defesa Social e Segurança Pública & 550 & 23,1 \\
Programa Território Aliança & 303 & 12,7 \\
Centro Integrado de Atendimento ao Adolescente Autor de Ato Infracional - GV & 470 & 19,7 \\
Gabinete de Gestão Integrada Municipal & 112 & 4,7 \\
Olho Vivo & 300 & 12,6 \\
Projeto Mulheres da Paz & 650 & 27,3 \\
Total & 2.385 & 100 \\
\hline
\end{tabular}

*Valor (em R\$ 1.000).

Fonte: elaboração própria a partir dos dados da Prefeitura Municipal de Governador Valadares, em 2014. 
Diante destes indicadores, cabe destacar que três dos seis destinos da despesa municipal são programas de caráter preventivo, referentes ao enfrentamento da violência. O primeiro, Programa Olho Vivo, consiste na instalação e manutenção de câmeras de segurança em pontos estratégicos de locais públicos, com maior incidência de crimes violentos contra o patrimônio, com o intuito de reprimir e ajudar a solucionar as ocorrências deste tipo; o segundo, Programa Território Aliança, que funciona em parceria com a Secretaria de Estado de Defesa Social (SEDS), tem por objetivo prevenir consumo de drogas e também acolher e tratar os indivíduos que já têm algum nível de dependência química, bem como seus respectivos familiares; e, por último, o Projeto Mulheres pela Paz, que busca capacitar mulheres que tenham algum nível de engajamento social dentro das comunidades vulneráveis, para desenvolver ações de promoção do emprego, cultura e esportes para jovens entre 14 e 24 anos, que já possuam histórico de criminalidade e/ ou uso de drogas. A soma destes três projetos equivale a 52,6\% do total da despesa municipal com segurança pública.

Com relação ao policiamento, o gasto total do governo estadual com a Polícia Militar de Minas Gerais (PMMG), no ano de 2015, foi de, aproximadamente, R\$ 10 bilhões. Neste mesmo ano, havia 41.261 policiais militares no estado de Minas Gerais; em Governador Valadares, o efetivo policial era de 1.063 indivíduos, o equivalente a 1 (um) PM para cada 248 habitantes (IMRS, 2018). Como o efetivo policial do município representa, aproximadamente, $2,57 \%$ em relação ao total do estado, foi considerado que as despesas estaduais com policiamento destinadas ao município foram equivalentes a esta proporção, gerando um gasto de aproximado de $\mathrm{R} \$ 26$ milhões.

De modo semelhante, o custo total do estado de MG com ações de reintegração social e custódia foi de, aproximadamente, R\$1,9 bilhão. Governador Valadares aloca três das 185 unidades prisionais do estado, o equivalente a 1,6\% do total. A partir desta proporção, foi considerado que as unidades prisionais do município geraram um custo aproximado de $R \$ 29$ milhões.

Quanto aos repasses do Sistema Único de Saúde para o município destinados ao atendimento médico das vítimas de violência por causas externas, no ano de 2015, o valor foi de $\mathrm{R} \$ 617$ mil, com um valor médio aproximado de R\$ 2 mil por internação. Aproximadamente $40 \%$ deste total foi destinado ao atendimento de vítimas com idade entre 15 e 29 anos, e $88 \%$ das vítimas atendidas se autodeclaravam pretas, pardas ou amarelas. Ainda, $90 \%$ das 297 internações por violência intencional atenderam vítimas do sexo masculino. Essas características revelam a associação da violência com as questões de gênero, raça e idade das vítimas. Os dados da Tabela 2 revelam os encargos por categoria, em 2015.

Tabela 2 - Encargos públicos por categoria - Governador Valadares, 2015

\begin{tabular}{lcc}
\hline Categoria de Gastos & $\mathbf{R}^{\mathbf{1}}$ & $\mathbf{( \% )}$ \\
\hline Segurança Pública & $2.385,5$ & 4,0 \\
Polícia Militar & $26.324,5$ & 45,06 \\
Reintegração Social e Custódia & $29.090,5$ & 49,8 \\
Atendimento Médico & 616,9 & 1,06 \\
Total & $58.417,4$ & 100 \\
\hline
\end{tabular}

*Valor (em R\$1.000).

Fonte: Elaboração própria a partir dos dados da Prefeitura Municipal de Governador Valadares, em 2014. 
Conforme descrito na Tabela 2, o encargo público relacionado à violência intencional contra terceiros no município de Governador Valadares foi de aproximadamente $\mathrm{R} \$ 58,5$ milhões, equivalente a 1,07\% do PIB local. Os gastos com a Polícia Militar, reintegração social e custódia foram os que tiveram maior peso dentro dos encargos públicos, representando $94 \%$ dos custos dentro da categoria.

No que se refere aos encargos privados diretos, com base nos dados da RAIS (BRASIL, 2018), para o total de profissionais de segurança com vínculo ativo (empregados em empresas privadas), no ano de 2015, foi possível obter a média de rendimento anual, como uma aproximação da despesa privada na contratação destes profissionais. Em 2015, Governador Valadares possuía 1.140 profissionais vinculados à atividade de segurança. Deste total, $95 \%$ dos profissionais eram do sexo masculino e obtiveram uma renda média mensal de $\mathrm{R} \$ 1.314,15$, enquanto as profissionais do sexo feminino, ocupando as mesmas funções, obtiveram uma renda média mensal de $\mathrm{R} \$$ 980,85 . O gasto total que as famílias e empresas tiveram com profissionais de segurança foi de, aproximadamente, $\mathrm{R} \$ 23,8$ milhões, o equivalente a 0,44\% do PIB local.

No que se refere aos gastos privados com seguros (Tabela 3), foram despendidos $R \$ 232$ milhões. Deste valor, $88,4 \%$ foram gastos com seguros de proteção veicular, 3,6\% foram gastos com proteção pessoal contra roubo e furto, e 7,8\% foram despendidos com proteção compreensiva para imóveis.

Tabela 3 - Gastos privados com seguros - Governador Valadares, 2015

\begin{tabular}{lcc}
\hline Categoria de Gastos & $\mathbf{R} \mathbf{\$}^{\mathbf{1}}$ & $\mathbf{( \% )}$ \\
\hline Seguro Veicular & $205.162,17$ & 88,4 \\
Seguro contra Roubo & $8.527,62$ & 3,6 \\
Seguros de Imóveis & $18.308,38$ & 7,8 \\
Total & $231.998,18$ & 100 \\
\hline
\end{tabular}

* Valor (em R\$ 1.000).

Fonte: elaboração própria a partir de dados da SUSEP (2018).

Os gastos totais com seguros, somados aos gastos com profissionais de segurança, geraram uma despesa de R\$256 milhões, o equivalente a 4\% do PIB local, sendo esta a categoria de maior peso dentro da análise geral. Uma vez que os seguros para veículos e imóveis cobrem outros danos, além dos relacionados a roubo e furto, estas informações podem estar superestimadas. No entanto, dada a disponibilidade dos dados, esta foi a maneira mais apropriada de medição, seguindo Rondon (2003) e Teixeira (2005), para a mensuração em Belo Horizonte e Curitiba, respectivamente.

Por fim, sobre as perdas sociais, a soma dos anos médios de vida perdidos (AVP) revelou que, no geral, os homens sofrem mais perdas de anos médios de vida do que as mulheres, principalmente para os que estão entre 15 e 49 anos de idade. No entanto o perfil das mulheres que mais perdem anos médios de vida é aquele que se encontra na fase de transição entre a adolescência e a juventude.

Em 2015, os homens do município de Governador Valadares perderam, em média, 0,314 anos de vida, enquanto a perda total das mulheres foi em média 0,023 anos. Embora a soma dos anos perdidos não tenha se aproximado da unidade, estes valores sugerem que existe o impacto direto das mortes prematuras por causas externas na expectativa de vida da população local e, 
também, evidenciam a maior vulnerabilidade dos homens em relação às mulheres. Além disso, os adolescentes e jovens estão mais expostos ao risco de morte prematura, em decorrência da violência.

No que tange à renda potencial perdida, obtida via análise conjunta de dados de mortalidade com dados de rendimento médio, ambos por sexo e faixa etária (Tabela 4), identifica-se que a morte prematura dos homens representou $90 \%$ da perda total, com um valor de R\$2,3 milhões. No tocante às mulheres, a perda total foi de R\$ 234 mil.

Tabela 4 - Renda potencial perdida por faixa etária - Governador Valadares, 2015 (em reais)

\begin{tabular}{|c|c|c|}
\hline Faixa Etária & Homem & Mulher \\
\hline 10 a 14 & $8.781,19$ & - \\
\hline 15 а 19 & $177.364,77$ & - \\
\hline 20 a 29 & $875.617,10$ & $63.685,93$ \\
\hline 30 а 39 & $485.180,57$ & $18.576,44$ \\
\hline 40 a 49 & $257.924,07$ & $100.790,90$ \\
\hline 50 a 59 & $104.517,84$ & $50.851,68$ \\
\hline 60 ou mais & $113.891,62$ & - \\
\hline Total por sexo & $2.023 .277,16$ & $233.904,95$ \\
\hline Total & \multicolumn{2}{|c|}{$2.257 .182,11$} \\
\hline
\end{tabular}

Fonte: Elaboração própria a partir dos dados do SIM (2018) e do MTE (2018).

Quando se consideram as rendas médias ponderadas pelos anos de estudo (Tabela 5), o total da renda potencial perdida, por sexo, é menor. No entanto estes valores mantêm a proporção de $90 \%$ das perdas totais representadas pelo sexo masculino e $10 \%$ para o sexo feminino. 0 valor total da renda potencial perdida, segundo os anos de estudo, foi de $\mathrm{R} \$ 1,2$ milhão para os homens e $\mathrm{R} \$ 150$ mil para as mulheres, totalizando, em média, $\mathrm{R} \$ 1,4$ milhão de perdas. Dado que uma das características das vítimas de Governador Valadares é ter baixa média de escolaridade, a análise do montante de renda potencial perdida ponderado pela escolaridade se mostra mais adequado.

Tabela 5 - Renda potencial perdida por anos de estudo - Governador Valadares, 2015 (em reais)

\begin{tabular}{lcc}
\hline \multicolumn{1}{c}{ Anos de Estudo } & Masculino & Feminino \\
\hline 0 a 3 & $338.771,9$ & $46.334,76$ \\
4 a 7 & $614.544,1$ & $50.473,55$ \\
8 a 11 & $286.674,8$ & $53.246,35$ \\
Total por sexo & $1.239 .990,80$ & $150.054,70$ \\
Total & \multicolumn{2}{c}{$1.390 .045,46$} \\
\hline
\end{tabular}

Fonte: elaboração própria a partir dos dados do SIM (2018) e da MTE (2018).

Partindo para a análise das perdas totais, a Tabela 6 apresenta as três categorias de custos e suas respectivas subcategorias, em proporção do PIB municipal de Governador Valadares, para 2015 (de R\$ 5,4 bilhões). 
Tabela 6 - Custos da violência, por categoria - Governador Valadares, 2015

\begin{tabular}{lcc}
\hline Categoria de Gastos & Valor (em R\$̧) & \% PIB \\
\hline & Encargos Públicos & \\
\hline Segurança Pública & $2.385 .500,00$ & 0,04 \\
Polícia Militar & $26.324 .459,02$ & 0,48 \\
Reintegração Social e Custódia & $29.090 .489,89$ & 0,54 \\
Atendimento Médico & $616.949,94$ & 0,01 \\
Total & $58.417 .398,85$ & 1,07 \\
\hline & Encargos Privados & \\
\hline Profissionais da Segurança & $23.754 .363,00$ & 0,44 \\
Seguros (Pessoal, Veicular e Imóvel) & $231.998 .180,29$ & 4,27 \\
Total & $255.752 .543,29$ & 4,70 \\
\hline & Perdas Sociais & \\
\hline Renda Potencial Perdida segundo Sexo, Faixa Etária e Anos de Estudo & $1.390 .045,46$ & 0,03 \\
Renda Potencial Perdida segundo Sexo e Faixa Etária & $2.257 .182,11$ & 0,042 \\
\hline & Encargos Totais & \\
\hline Total (Sexo, Faixa Etária e Anos de Estudo) & $315.559 .987,60$ & 5,8 \\
Total (Sexo e Faixa Etária) & $316.427 .124,25$ & 5,82 \\
\hline
\end{tabular}

Fonte: Elaboração própria a partir dos dados do SIM (2018) e do MTE (2018).

O custo total da violência em Governador Valadares, no ano de 2015, representou 5,8\% do PIB municipal. Cabe destacar que este resultado é superior àqueles encontrados para Belo Horizonte e para Curitiba, nos anos de 2002 e 2005, os quais apresentaram um gasto total de $3,9 \%$ e $2,26 \%$ de seus PIBs, respectivamente. No entanto os resultados aqui encontrados são semelhantes a estes trabalhos no que tange ao "ranking" dos pesos de cada categoria, estando em primeira posição os encargos privados; em segunda, os encargos públicos; e em terceira, as perdas sociais, o que fortalece os resultados.

No tocante à desagregação das categorias de custos para o município de Governador Valadares, os encargos privados consumiram um montante de $4 \%$ do PIB, revelando o perfil da demanda da população por alternativas para se sentirem mais protegidos. Neste quesito, apesar da demanda por profissionais da segurança estar em tendência de crescimento, esta demanda representa aproximadamente $10 \%$ dos gastos privados, enquanto os gatos com seguros para automóveis representam $80 \%$.

Já os encargos públicos foram equivalentes a 1,07\% do PIB municipal. Vale lembrar que, em relação aos gastos com a saúde, o governo federal custeia apenas uma parte dos custos envolvidos no atendimento médico às vítimas da violência. Assim, os valores totais dos encargos públicos podem estar subestimados. No entanto, uma vez que os demais gastos envolvidos não são passíveis de desagregação por atendimento, tal como os gastos com profissionais da saúde e equipamentos médicos, esta maneira é a mais adequada para a medição dos gastos relacionados à saúde.

É possível observar que, embora os gastos privados tenham sido maiores que os gastos públicos, os primeiros servem basicamente para aumentar a proteção individual ou a sensação de maior segurança (tanto para famílias quanto para empresas), gerando resultados apenas no tempo t em que estes gastos são realizados. Os gastos públicos, por sua vez, são destinados para combater a violência efetiva, seja pela presença policial, seja pela instalação de meios de monitoramento, e os programas de prevenção são direcionados, principalmente, aos jovens e à 
população mais vulnerável, de modo que os resultados destes gastos e/ou investimentos podem vir a ser observados também no longo prazo.

Por seu turno, as perdas sociais foram de $0,04 \%$ do PIB, independentemente de se considerar o nível de escolaridade das vítimas. Apesar disso, quando os anos de estudo são considerados, a perda social equivale a $\mathrm{R} \$ 867$ mil a menos do que na estimativa em que a escolaridade das vítimas não é considerada. Uma vez que o perfil das vítimas de violência se caracteriza, entre outras coisas, pela baixa escolaridade, o cálculo que considera esta variável se mostra mais adequado na tentativa de se obter valores relativamente mais realísticos.

Segundo Rodriguez-Ortiz (2017), o custo do crime na América Latina e no Caribe é duas vezes o custo médio dos países desenvolvidos. A região apresenta custos sociais mais altos e duas vezes o gasto privado com segurança como parcela do PIB. A parcela do gasto público com segurança na América Latina e no Caribe como parcela do gasto público total é quase duas vezes a média dos países desenvolvidos, demonstrando a prioridade que os governos da América Latina e Caribe atribuem à segurança cidadã.

Entretanto, segundo Teixeira (2005), não é adequado classificar todos esses valores em altos ou baixos, dadas as especificidades econômicas e sociais de cada região analisada, porém tais informações se mostram suficientes para análises acerca das perdas totais e da alocação dos recursos públicos, podendo ser acompanhadas ao longo do tempo.

Por fim, algumas estratégias de prevenção citadas no relatório do CRISP (2016) encontramse inseridas na Política de Prevenção do Governo do Estado. Tratam-se de quatro intervenções distintas, operacionalizadas em nível local, por técnicos ligados à Coordenadoria Especial de Prevenção à Criminalidade da Secretaria de Estado de Defesa Social (CPEC/SEDS). A primeira trata do programa "Fica Vivo!", que visa prevenir a ocorrência de homicídios dolosos em áreas com altos índices de criminalidade violenta; o segundo programa, intitulado "Central de Acompanhamento às Penas e Medidas Alternativas", tem o objetivo de criar estruturas capazes de monitorar todo o processo do acompanhamento e da fiscalização das penas alternativas não privativas de liberdade e reintegração social; o terceiro, chamado de "Mediação de Conflitos", visa empreender ações de mediações, articulação e fomento à organização em comunidade e institucional, possibilitando a administração de conflitos potenciais e concretos; e o quarto, chamado de "Programa de Reintegração Social de Egressos do Sistema Prisional" (PrEsp), que almeja diminuir as exclusões e estigmas decorrentes da experiência prisional, bem como buscar o distanciamento do egresso das condições que ampliam reincidência criminal.

\section{CONSIDERAÇÕES FINAIS}

O presente trabalho teve o objetivo de mensurar e analisar os custos impostos ao município de Governador Valadares, MG, pela violência intencional contra terceiros, no ano de 2015. O método empregado foi o de contagem, cuja vantagem é a possibilidade de trabalhar com informações parciais, conforme a disponibilidade de dados. Embora o método de contagem possa não ser preciso, estas estimativas servem para levantar o debate acerca do impacto da violência em nível local, nortear a tomada de decisões quanto às políticas públicas a serem adotadas, bem como para revelar o perfil das vítimas e da demanda privada por segurança.

Uma vez que a caracterização das vítimas de violência em Governador Valadares está relacionada às vulnerabilidades socioeconômicas, a saber, fragilidade financeira, desestruturação 
familiar e baixa escolaridade, atingindo principalmente os mais jovens, conclui-se que as teorias aqui apresentadas contribuem para a explicação dos determinantes da criminalidade no município.

Os resultados mostraram que os encargos públicos, encargos privados e as perdas de rendas potenciais foram equivalentes a 1,07\%, 4,7\% e 0,04\% do PIB municipal, respectivamente. O valor das perdas agregadas chegou a aproximadamente $R \$ 316$ milhões, ou o equivalente a 5,8\% do PIB municipal. Tais resultados permitem inferir que, na ausência da violência, o montante perdido em relação ao PIB poderia ser empregado em outros setores da economia, como educação, cultura e promoção do emprego e renda, contribuindo para um ambiente mais favorável ao crescimento e desenvolvimento socioeconômico.

Por fim, as análises quantitativas reveladas neste artigo indicam apenas uma parcela das perdas econômicas tangíveis associadas à violência. A perda de bem-estar e os prejuízos envolvendo o capital humano e o capital social, por exemplo, não estão avaliados nas categorias aqui analisadas, tornando-se uma importante proposta de extensão deste trabalho. É preciso reconhecer essas limitações deste estudo, além da necessidade de uma análise complementar e detalhada envolvendo as políticas públicas e estruturas sociais capazes de combater a violência. As políticas de caráter preventivo, referentes a projetos na área de educação, redistribuição de renda e cultura, podem ser instrumentos capazes de reverter as altas taxas de homicídios em Governador Valadares.

De toda forma, a principal contribuição desta pesquisa foi de mensurar as perdas financeiras advindas da violência para o município de Governador Valadares, MG, servindo de parâmetro para o acompanhando dessas medidas para formuladores de políticas públicas, ao longo do tempo.

\section{REFERÊNCIAS}

ALMEIDA, E. S. Criminalidade violenta no estado de Minas Gerais em 2005: um modelo explicativo. Revista de História Econômica \& Economia Regional Aplicada, Juiz de Fora, v. 7, n. 12, p. 90-109, 2012.

ALMEIDA, M. A. S.; GUANZIROLI, C. E. Criminalidade na região metropolitana de Belo Horizonte: o que a teoria econômica é capaz de explicar? Pesquisa \& Debate, São Paulo, v. 24, n. 2, p. 171-96, 2013. Disponível em: https://revistas.pucsp.br/index.php/rpe/article/viewFile/17709/13198. Acesso em: 10 dez. 2017.

ANDRADE, M. V.; PEIXOTO, B. T. Avaliação econômica de programas de prevenção e controle da criminalidade no Brasil. Belo Horizonte: UFMG, 2007. (Texto para discussão, n. 311). Disponível em: https://core.ac.uk/download/pdf/6520054.pdf. Acesso em: 10 dez. 2017.

BANCO INTERAMERICANO DE DESARROLLO [BID]. Fundación Mexicana para la Salud. La violencia en La Ciudad de México: análisis de la magnitud y su repercusión económica. Washington, D.C., 1997.

BECKER, G. S. Crime and punishment: an economic approach. Journal of Political Economy, Chicago, v. 76, n. 2, p. 169-217, 1968.

BECKER, K. L.; KASSOUF, A. L. Uma análise do efeito dos gastos públicos em educação sobre a criminalidade no Brasil. Economia e Sociedade, Campinas, v. 26, n. 1, p. 215-42, 2017. Disponível em: http://www.scielo. br/pdf/ecos/v26n1/1982-3533-ecos-26-01-00215.pdf. Acesso em: 15 jan. 2018.

BRASIL. Ministério do Trabalho e Emprego [MTE]. Relação Anual de Informações Sociais - RAIS - dados 2015. Brasília-DF: MTE, 2018. Disponível em: http://www.rais.gov.br/sitio/index.jsf Acesso em: 20 jun. 2017. 
CAPRIROLO, D.; JAITMAN, L.; MELLO, M. Os custos de bem-estar do crime no Brasil: um país de contrastes. In: BANCO INTERAMERICANO DE DESENVOLVIMENTO [BID]. Os custos do crime e da violência: novas evidências e constatações na América Latina e Caribe. Nova York: Editora Laura Jaitman/BID, 2017.

CENTRO DE ESTUDOS DE CRIMINALIDADE E SEGURANÇA PÚBLICA [CRISP]. Relatório de pesquisa: pensando a segurança pública: homicídios no Brasil, 2016. Disponível em: http://www.bibliotecadigital.mg.gov.br/ consulta/consultaDetalheDocumento.php?iCodDocumento=56306 Acesso em: 20 jun. 2017.

CERQUEIRA, D. R. C. Causas e consequências do crime no Brasil. 2014. Tese (Doutorado em Economia) Pontifícia Universidade Católica do Rio de Janeiro, Rio de Janeiro, RJ, 2014.

CERQUEIRA, D. R. C.; MOURA, R. L. Demografia e homicídios no Brasil. In: CAMARANO, A. A. (Org.). Novo regime demográfico: uma nova relação entre população e desenvolvimento? 1. ed. Brasília: IPEA, 2014. p. 355-73.

CERQUEIRA, D. Trajetórias individuais, criminalidade e o papel da educação. Boletim de Análise PolíticoInstitucional, Brasília, n. 9, jan./jun. 2016.

CERQUEIRA, D.; LIMA, R. S.; BUENO, S.; VALENCIA, L. I.; HANASHIRO, O.; MACHADO, P. H. G.; LIMA, A. S. Atlas da violência 2017. Rio de Janeiro: IPEA, 2017. Disponível em: http://www.ipea.gov.br/portal/ images/170602_atlas_da_violencia_2017.pdf. Acesso em: 15 jan. 2018.

CERQUEIRA, D.; LOBÃO, W. Determinantes da criminalidade: arcabouços teóricos e resultados empíricos. Revista de Ciências Sociais, Rio de Janeiro, v. 47, n. 2, p. 233-69, 2004.

CERQUeIRA, D.; MOURA, R. Custo da Juventude Perdida no Brasil. Observatório de Segurança, jul. 2013. Disponível em: http://www.observatoriodeseguranca.org/files/Custo_da_juventude_perdida_no_Brasil_ IPEA_jul_2013_0.pdf. Acesso em: 5 out. 2017.

COHEN, L.; FELSON, M. Social change and crime rate trends: a routine approach. American Sociological Review, v. 44, n. 4, p. 588-608, 1979. Disponível em: https://www.jstor.org/stable/2094589?seq=1\#page_ scan_tab_contents. Acesso em: 25 ago. 2017.

DATASUS. Informações de saúde. Brasília-DF, 2018. Disponível em: http://datasus.saude.gov.br/ informacoes-de-saude/tabnet. Acesso em: 31 jan. 2018.

DEPARTAMENTO PENITENCIÁRIO NACIONAL [DEPEN]. Dados gerais 2018. Brasília-DF, DEPEN, 2018. Disponível em: https://www.gov.br/depen/pt-br. Acesso em: 31 jan. 2018.

FEARON, J.; HOEFFLER, A. Conflict and violence assessment paper: benefits and costs of the conflict and violence targets for the post-2015 development agenda. Copenhagen: Copenhagen Consensus Center, 2014. Disponível em: https://www.copenhagenconsensus.com/sites/default/files/conflict_assessment_-_ hoeffler_and_fearon_0.pdf. Acesso em: 25 ago. 2017.

FUNDAÇÃO JOÃO PINHEIRO [FJP]. Índice mineiro de responsabilidade social. IMRS, Belo Horizonte, 2018. Disponível em: http://imrs.jp.mg.gov.br/. Acesso em: 31 jan. 2018.

GOVERNADOR VALADARES (Cidade). Relatório resumido de execuções orçamentárias do município de Governador Valadares. Governador Valadares: Prefeitura Municipal, 2016. Disponível em: http://transparencia.valadares.mg.gov.br/abrir_arquivo.aspx/Relatorio_Resumido_da_Execucao_ Orcamentaria_65_1_Bimestre_2014?cdLocal=6\&arquivo=\%7B71BC46C4-2BAB-ABD1-5DAA2ACA47BDCCDA\%7D.PDF. Acesso em: 31 jan. 2018. 
INSTITUTO BRASILEIRO DE GEOGRAFIA E ESTATÍSTICA [IBGE]. Cidades. Rio de Janeiro: IBGE, 2018. Disponível em: https://cidades.ibge.gov.br/. Acesso em: 31 jan. 2018.

INSTITUTO DE ESTUDOS DA RELIGIÃO [ISER]. Magnitude, custos econômicos e políticas de controle da violência no Rio de Janeiro. Washington, DC: Banco Interamericano de Desenvolvimento, 1998. Disponível em: https://idblegacy.iadb.org/res/laresnetwork/files/pr35finaldraft.pdf. Acesso em: 25 ago. 2017.

KHAN, T. Os custos da violência: quanto se gasta ou deixa de ganhar por causa do crime no Estado de São Paulo. São Paulo em perspectiva, São Paulo, v. 13, n. 4, p. 42-8, 1999. Disponível em: http://www.scielo. br/pdf/spp/v13n4/v13n4a04.pdf. Acesso em: 10 set. 2017.

LOUREIRO, A. O.; CARVALHO-JUNIOR, J. R. A. O impacto dos gastos públicos sobre a criminalidade no Brasil. In: ENCONTRO NACIONAL DE ECONOMIA, 35., 4 a 7 de dezembro de 2007, Recife. Anais [...]. Brasília: ANPEC, 2007. Disponível em: http://www.anpec.org.br/encontro2007/artigos/A07A163.pdf. Acesso em: 25 ago. 2017.

MARQUES JUNIOR, K. A renda, desigualdade e criminalidade no Brasil: uma análise empírica. Revista Econômica do Nordeste, Fortaleza, v. 45, n. 1, p. 34-46, jan./mar. 2014. Disponível em: https://ren. emnuvens.com.br/ren/article/view/62/42. Acesso em: 10 set. 2017.

ORGANIZAÇÃO DAS NAÇÕES UNIDAS [ONU]. Declaração Universal dos Direitos Humanos. Brasília-DF: ONU, 1948. Disponível em: http://www.onu.org.br/img/2014/09/DUDH.pdf. Acesso em: 10 set. 2017.

ORGANIZAÇÃO MUNDIAL DA SAÚDE [OMS]. Classificação internacional de doenças CID10. Genebra: OMS, 2017a. Disponível em: http://www.who.int/. Acesso em: 30 Ago. 2017.

ORGANIZAÇÃO MUNDIAL DA SAÚDE [OMS]. Dados gerais. OMS, 2017b. Disponível em: http://www.who. int/. Acesso em: 30 ago. 2017.

PEIXOTO, B. T.; ANDRADE, M. V.; AZEVEDO J. P. Prevenção e controle de homicídios: uma avaliação de impacto no Brasil. Belo Horizonte: UFMG/CEDEPLAR/FACE, 2008. (Texto para discussão, n. 337). Disponível em: https://core.ac.uk/download/pdf/6519996.pdf. Acesso em: 10 set. 2017.

QUINNEY, R. Criminology. 2. ed. Boston: Little, Brown and Company, 1979.

RODRIGUEZ-ORTIZ, A. M. Banco Interamericano de Desenvolvimento [BID]. Os custos do crime e da violência: novas evidências e constatações na América Latina e Caribe. [Prefácio]. Nova York: Editora Laura Jaitman / BID, 2017.

RONDON, V. V. Custos da criminalidade no município de Belo Horizonte: duas abordagens sobre a perda de bem-estar. 2003. Dissertação (Mestrado em Economia) - Universidade Federal de Minas Gerais, Belo Horizonte, MG, 2003.

RONDON, V. V.; ANDRADE, M. V. Custo da criminalidade em Belo Horizonte. EconomiA, Niterói, v. 4, n. 2, p. 223-59, 2003. Disponível em: https://anpec.org.br/revista/vol4/v4n2p223_259.pdf. Acesso em: 10 set. 2017.

SANTOS, C. A.; CASAGRANDE, D.; HOECKEL, P. H. Teoria econômica do crime: dos pressupostos acadêmicos à empiria do dia a dia na vida de ex presidiários de Santa Maria RS. Economia e Desenvolvimento, Santa Maria, v. 27, n. 2, p. 308-25, 2015. Disponível em: https://periodicos.ufsm.br/eed/article/view/21087/ pdf. Acesso em: 15 nov. 2017. 
SANTOS, M. J.; KASSOUF, A. L. Estudos econômicos das causas da criminalidade no Brasil: evidências e controvérsias. Economia, Brasília, v. 9, n. 2, p. 343-72, maio/ago. 2008. Disponível em: http://www.anpec. org.br/revista/vol9/vol9n2p343_372.pdf. Acesso em: 15 nov. 2017.

SANTOS, W. F.; ABREU, J. L. N. Modernização e utopias: projetos de transformação urbana no município de Governador Valadares (1960-80). Revista Ágora, Vitória, n. 10, p. 1-15, 2009. Disponível em: http:// www.periodicos.ufes.br/agora/article/viewFile/1944/1456. Acesso em: 10 set. 2017.

SAPORI, L. F. Segurança pública no Brasil: desafios e perspectivas. Rio de Janeiro: Editora FGV, 2007.

SISTEMA DE INFORMAÇÕES HOSPITALARES [SIHSUS]. Dados gerais. Brasília: Datasus, 2018. Disponível em: http://datasus.saude.gov.br/sistemas-e-aplicativos/hospitalares/sihsus. Acesso em: 31 jan. 2018.

SISTEMA DE INFORMAÇÕES SOBRE MORTALIDADE [SIM]. Dados gerais. Brasília: Datasus, 2018. Disponível em: http://datasus.saude.gov.br/sistemas-e-aplicativos/eventos-v/sim-sistema-de-informacoes-demortalidade. Acesso em: 31 jan. 2018.

SUPERINTENDÊNCIA DE SEGUROS PRIVADOS [SUSEP]. Dados Gerais. 2018. Disponível em: http://www. susep.gov.br/. Acesso em: 31 jan. 2018.

TEIXEIRA, E. C. Estimando o impacto econômico da violência: custos da criminalidade em Curitiba. 123 f. 2005. Dissertação (Mestrado em Desenvolvimento Econômico) - Universidade Federal do Paraná, Curitiba, PR, 2005. Disponível em: https://acervodigital.ufpr.br/handle/1884/2024. Acesso em: 10 set. 2017.

THOMÉ, D. B.; VONBUN, C. Análise do impacto dos gastos públicos com programas de transferência de renda sobre a criminalidade. Brasília, 2017. (Texto para discussão, n. 2315). Disponível em: http://www. ipea.gov.br/portal/images/stories/PDFs/TDs/td_2315.pdf. Acesso em: 15 jan. 2018.

\section{Sobre os autores:}

Hilton Manoel Dias Ribeiro: Doutor em Economia pela Universidade Federal de Juiz de Fora (UFJF). Mestre em Economia pela Universidade Federal de Viçosa (UFV). Especialista em Gestão Pública pela Universidade Federal de Santa Maria (UFSM). Professor adjunto no Departamento de Economia da UFJF, Campus GV. Tem experiência em políticas públicas na área de inovação e desenvolvimento regional em Minas Gerais. Interessado em pesquisas nas áreas de Economia Institucional, Regional, Economia Mineira, Inovação e Políticas Públicas. E-mail: hilton.manoel@ufjf.edu.br, Orcid: http://orcid.org/0000-0003-2729-9674

Oline Silva Freitas: Economista pela Universidade Federal de Juiz de Fora (UFJF), Campus GV. Tem experiência em pesquisa e atividades de extensão, com foco em desenvolvimento local e regional. Colaboradora do Grupo de Pesquisa Econúcleo - Estudos Socioeconômicos. E-mail: olinesfreitas@hotmail.com, Orcid: http://orcid.org/0000-0002-5351-1264 
